\title{
Isolation and Biochemical Characterization of Rhizobium Leguminosarum bv. Trifolii and Sinorhizobium Meliloti using API 20 NE and API 20 E
}

\author{
Monica NISTE, Roxana VIDICAN*, Carmen PUIA, Ioan ROTAR, Rodica POP \\ University of Agricultural Sciences and Veterinary Medicine, ClujNapoca, Faculty of Agriculture, \\ Manastur Street, No. 3-5, 400372, Cluj-Napoca, Romania \\ * corresponding author: roxana.vidican@usamvcluj.ro \\ Bulletin USAMV series Agriculture 72(1)/2015 \\ Print ISSN 1843-5246; Electronic ISSN 1843-5386 \\ DOI 10.15835/buasvmcn-agr: 11178
}

\begin{abstract}
The present study was carried out to isolate and to investigate biochemical characteristics of twenty rhizobacteria strains from red clover (Rhizobium trifolii) and alfalfa (Sinorhizobium meliloti). The result of the study showed a low diversity in morphological, physiological and symbiotic properties among the rhizobial strains. Phenotypically all isolated strains had the same colony morphology conical with a smooth margin, the color and texture was watery to translucent. The isolates were fast-growing and failed to absorb Congo red. API 20NE and API 20E showed a negative reaction for the reduction of nitrate in RtS1, RtR2, and positive for SmM1, SmM2. The reaction was positive for $\beta$-galactosidase, $\beta$-glucosidase and negative for urease, arginine dihydrolase, for all rhizobial isolates. Carbon sources: glucose, arabinose, mannose,mannitol, maltose, were also positive for all strains. Rhizobial strains utilized a wider range of carbohydrates and this may be a helpful tool for the characterization of the isolates.
\end{abstract}

Keywords: bacterial characterization, biochemical tests, rhizobial strains.

\section{INTRODUCTION}

The biological nitrogen fixation (BNF) is a major contributor of nitrogen to the rhizosphere. Most of fixed nitrogen provided by BNF is from Rhizobium-legume symbiosis (Prayitno and Rolfe, 2010). Values estimated for various legume crops and pasture species are often impressive, commonly falling in the range $200-300 \mathrm{~kg} \mathrm{~N}$ $\mathrm{ha}^{-1}$ per year. This underlines the significance of Rhizobium-legume symbiosis as a major contributor to BNF (Zahran, 2001). Members of the genus Rhizobium are known for their ability to establish symbiotic interactions with leguminous plants by the formation and colonization of root nodules. They elicit the formation of specialized organs called nodules, where bacteria fix nitrogen to ammonia and make it available for the plant (Sessitsch et al., 2002). The bacteria are mostly rhizospheric microorganisms, despite its ability to live in the soil for long period of time (Shridhar, 2012). The bacteria enzyme system supplies a constant source of reduce nitrogen to the host plant and the plant furnishes nutrients and energy for the activities of the bacteria (Shetta et al., 2011).

Most bacteria have a specific host, but there are several different bacterial species that are also isolated from a single legume species, and these bacteria are characterized into two groups on the basis of growth rate (Deshwal and Chaubey, 2014). 
Classification according to their speed of growth on artificial media divides the rhizobia into two classes, the fast growers and the slow growers. There are some differences between these two classes of rhizobia on the basis of growth rate and effect on the $\mathrm{pH}$ of yeast extract-mannitol (YEM) medium under standard laboratory conditions. The fast-growing rhizobia have mean generation times of 2 to $4 \mathrm{~h}$ and produce a net decrease in the $\mathrm{pH}$ of YEM culture medium, whereas the rhizobia referred to as slow growing have mean generation times of $6 \mathrm{~h}$ and longer and do not lower the $\mathrm{pH}$ of this medium (Sadowsky et al., 1983).

Classification of rhizobia according to the host legumes they can nodulate divides them into crossinoculation groups (Greenwood and Pankhurst, 1977). Each major legume group is nodulated by different species of Rhizobium. Red clover is nodulated by Rhizobium leguminosarum biovar. trifolii and alfalfa is nodulated by Sinorhizobium meliloti. The genus Rhizobium was erected by Frank (1932) based on its characters to form nodules on roots of legume plants (Gachande and Khansole, 2011).

The objective of this study was to isolate the rhizobial strains from the root nodules of red clover (Trifolium pratense $\mathrm{L}$ ) and alfalfa (Medicago sativa L.) and to characterize them using various cultural and biochemical tests.

\section{MATERIALS AND METHODS}

This study was conducted in the greenhouse and laboratory of University of Agricultural and Veterinary Medicine from Cluj-Napoca. Rhizobial isolates used in this study were obtained from red clover (Trifolium pratense L.) and alfalfa (Medicago sativa L.) grown in vegetation plots. Total of 20 samples (five for each variety) of root nodules from alfalfa (Medico sativa with two varieties Mădălina and Mihaela) and from red clover (Trifolium pratense L. also with two varieties Rotrif and Select 2) were collected for the biochemical characterization.

Healthy root nodules from clover and alfalfa were removed from vegetation plots transferred to the laboratory for immediate testing. Root nodules were washed with tape water two times to remove soil. The first step was the examination of the nodules under the microscope to observe the cell shape. After that the nodules were sterilized externally using $95 \%$ alcohol for 1-4 minute, followed by immersing the nodules in sodium hypochlorite (Domestos commercial solution) for 5 minutes, after that they were washed with sterile water. The treatment was followed by five changes in sterile water using sterile forceps to transfer the nodules. Well sterilized nodules were crushed into the surface of Yeast Extract Mannitol Agar (YEMA) and the plates were then incubated at $28^{\circ} \mathrm{C}$ in the dark for 72 hours. After that the pure isolated typical single colonies were restreaked on freshly prepared YEMA plates in order to obtain pure cultures. Bacteria were isolated from red clover and alfalfa using an abbreviation of the Rhizobium strains followed by the name of host legume i.e. RtR, RtS, SmM and SmI.

Rhizobium strains were subjected to different cultural characterization (shape, texture, colour, size) and Gram staining was performed. All the collected samples were processed through different biochemical tests using a standardized system API $20 \mathrm{NE}$ and API $20 \mathrm{E}$ in order to see some differences between strains of red clover and alfalfa.

The API $20 \mathrm{NE}$ and $20 \mathrm{E}$ strips consists of 20 microtubes containing dehydrated substrates. These tests are inoculated with a bacterial suspension that reconstitutes the media. During incubation, metabolism produces color changes that are either spontaneous or revealed by the addition of reagents. The assimilation tests are inoculated with a minimal medium and the bacteria grow if they are capable of utilizing the corresponding substrate. The reaction are interpret according to the reading table.

\section{RESULTS AND DISCUSSION}

Root nodulating bacteria were isolated from red clover and alfalfa, and the growth period of the isolate was between 3 and 5 days which indicated that isolates were fast grower. Bacterial isolates examined had rod-shape and occurred singly. All isolates were Gram-negative and did not absorb congo red when were incubated in the dark.

Results of bacterial characterization indicated that isolates from red clover and alfalfa shared common features, the diameter of colonies was between 2 and $4 \mathrm{~mm}$ after 5 days incubation. Isolates from alfalfa which had the colony smoth flat and domed compared with isolates from red clover which had the colony varying from flat to dome but there were some conical colonies as 
well. The colour of the colonies differ from milky to watery-transluscent (Tab. 1).

API 20 NE and 20 E have in common a few tests, some with the same name some with different abbreviation but the active ingredients are the same for example in API 20 NE $\beta$-Galactopyranosidase is noted as PNPG and in API $20 \mathrm{E}$ as ONPG. For all bacterial isolates, $ß$-Galactosidase emerged as positive in both tests. The production of indole (TRP) was variable in API $20 \mathrm{NE}$ for RtS and RtR but in API $20 \mathrm{E}$ the indole production (IND) was negative for the same isolates. In the case of SmM and SmI isolates, the production of indole was negative in both API tests. Gelatinase (GEL) and arginine dihydrolase (ADH) tests resulted as negative for all isolates in both API systems. Urease (URE) test is also a common test which resulted negative for the bacterial isolates.

In API $20 \mathrm{NE}$ nitrate reduction $\left(\mathrm{NO}_{3}\right)$ was negative for RtS1, RtR2 and positive for SmM1, SmM2. ß-Glucosidases (ESC) is a test present only in API $20 \mathrm{NE}$ and had a positive reaction which means that all the isolates have consumed the substrate (Tab. 2 and Tab. 3).

Lysine decarboxylase (LDC) and ornithine decarboxylase (ODC) was negative for RtS and RtR and positive for SmM and SmI in API 20 E. The samples used in this study were found negative for sodium thiosulfate production $\left(\mathrm{H}_{2} \mathrm{~S}\right)$, Voges Proskauer (VP) and citrate utilization (CIT) tests which mean that the bacteria didn't consummate the substrate. Graham and Parker (1964) reported thet the production of $\mathrm{H}_{2} \mathrm{~S}$ and citrate utilization were restricted to some isolates of Rhizobium meliloti and for Rhizobium trifolii was negative for all isolates, the results are consistent with our results. Tryptophane deaminase test present in API $20 \mathrm{E}$ resulted as positive for all isolates (Tab. 4 and Tab. 5).

Isolates have not varied regarding the utilization of different carbon sources. Rhizobial strains analyzed in this study showed full grown in response to glucose (GLU), arabinose (ARA), mannose (MNE), mannitol (MAN), N-acetylglucosamine (NAG) and maltose (MAL) in API

Tab. 1 Morphological and physiological characteristics of the bacterial isolates

\begin{tabular}{|c|c|c|c|c|c|c|}
\hline Host legume & Isolate & $\begin{array}{c}\text { Growth } \\
\text { period } \\
\text { (days) }\end{array}$ & $\begin{array}{c}\text { Gram } \\
\text { reaction }\end{array}$ & Shape & Colony morphology & Colour \\
\hline T. pratense & RtS1 & $3-5$ & - & rod & Mucoid, flat, entire & Watery to translucent \\
\hline T. pratense & RtS2 & $3-5$ & - & rod & Mucoid, flat, entire & Watery to translucent \\
\hline T. pratense & RtS3 & $3-5$ & - & rod & Mucoid, flat, entire & Watery to translucent \\
\hline T. pratense & RtS4 & $3-5$ & - & rod & Mucoid, flat, entire & Watery to translucent \\
\hline T. pratense & RtS5 & $3-5$ & - & rod & Mucoid, flat, entire & Watery to translucent \\
\hline T. pratense & RtR1 & $3-5$ & - & rod & Mucoid, domed, entire & Watery to translucent \\
\hline T. pratense & RtR2 & $3-5$ & - & rod & Mucoid, conical, entire & Watery to translucent \\
\hline T. pratense & RtR3 & $3-5$ & - & rod & Mucoid, domed, entire & Watery to translucent \\
\hline T. pratense & RtR4 & $3-5$ & - & rod & Mucoid, conical, entire & Watery to translucent \\
\hline T. pratense & RtR5 & $3-5$ & - & rod & Mucoid, domed, entire & Watery to translucent \\
\hline M. sativa & SmM1 & $3-5$ & - & rod & Smooth, flat, entire & Milky translucent \\
\hline M. sativa & SmM2 & $3-5$ & - & rod & Smooth, flat, entire & Milky translucent \\
\hline M. sativa & SmM3 & $3-5$ & - & rod & Smooth, flat, entire & Milky translucent \\
\hline M. sativa & $\mathrm{SmM} 4$ & $3-5$ & - & rod & Smooth, flat, entire & Milky translucent \\
\hline M. sativa & SmM5 & $3-5$ & - & rod & Smooth, domed, entire & Milky translucent \\
\hline M. sativa & SmI1 & $3-5$ & - & rod & Smooth, domed, entire & Milky translucent \\
\hline M. sativa & SmI2 & $3-5$ & - & rod & Smooth, domed, entire & Milky translucent \\
\hline M. sativa & SmI3 & $3-5$ & - & rod & Smooth, domed, entire & Milky translucent \\
\hline M. sativa & SmI4 & $3-5$ & - & rod & Smooth, flat, entire & Milky translucent \\
\hline M. sativa & SmI5 & $3-5$ & - & rod & Smooth, domed, entire & Milky translucent \\
\hline
\end{tabular}


Tab. 2 API 20 NE test results of the Rhizobium trifolii isolates after incubation at $28^{\circ} \mathrm{C}$ for 48 hours

\begin{tabular}{|c|c|c|c|c|c|c|c|c|c|c|c|}
\hline \multirow{2}{*}{ Tests } & \multirow{2}{*}{ Substrates } & \multicolumn{10}{|c|}{ Isolates } \\
\hline & & RtS1 & RtS2 & RtS3 & RtS4 & RtS5 & RtR1 & RtR2 & RtR3 & RtR4 & RtR5 \\
\hline $\mathrm{NO}_{3}$ & Potassium nitrate & - & - & - & - & - & - & - & - & - & - \\
\hline TRP & Tryptophane & - & - & - & + & - & + & - & + & + & + \\
\hline GLU & Glucose & + & + & + & + & + & + & + & + & + & + \\
\hline $\mathrm{ADH}$ & Arginine & - & - & - & - & - & - & - & + & - & + \\
\hline URE & Urea & + & + & + & + & + & + & + & + & + & + \\
\hline ESC & Esculin & + & + & + & + & + & + & + & + & + & + \\
\hline GEL & Gelatine & - & - & - & - & - & - & - & - & - & - \\
\hline PNPG & $\beta$ galactopyranoside & + & + & + & + & + & + & + & + & + & + \\
\hline GLU & Glucose & + & + & + & + & + & + & + & + & + & + \\
\hline ARA & Arabinose & + & + & + & + & + & + & + & + & + & + \\
\hline MNE & Mannose & + & + & + & + & + & + & + & + & + & + \\
\hline MAN & Manitol & + & + & + & + & + & + & + & + & + & + \\
\hline NAG & $\mathrm{N}$-acetyl-glucosamine & + & + & + & + & + & + & + & + & + & + \\
\hline MAL & Maltose & + & + & + & + & + & + & + & + & + & + \\
\hline GNT & Gluconate & - & - & - & - & - & - & - & - & - & - \\
\hline CAP & Caprate & - & - & - & - & - & - & - & - & - & - \\
\hline $\mathrm{ADI}$ & Adipate & - & - & - & - & - & - & - & - & - & - \\
\hline MLT & Malate & - & - & - & + & - & + & + & + & - & - \\
\hline CIT & Citrate & + & + & - & - & - & + & + & + & - & + \\
\hline
\end{tabular}

$(+)$ means that Rhizobia isolate has consumed the substrate (change the colour), $(-$ ) means that Rhizobia isolate had not consumed the substrate (no colour change)

Tab. 3 API 20 NE test results of the Sinorhizobium meliloti isolates after incubation at $28^{\circ} \mathrm{C}$ for 48 hours

\begin{tabular}{|c|c|c|c|c|c|c|c|c|c|c|c|}
\hline \multirow{2}{*}{ Tests } & \multirow{2}{*}{ Substrates } & \multicolumn{10}{|c|}{ Isolates } \\
\hline & & SmM1 & SmM2 & SmM3 & SmM4 & SmM5 & SmI1 & SmI2 & SmI3 & SmI4 & SmI5 \\
\hline $\mathrm{NO}_{3}$ & Potassium nitrate & - & - & - & - & - & - & - & - & - & - \\
\hline TRP & Treptophane & - & - & - & - & - & - & - & - & - & - \\
\hline GLU & Glucose & + & + & + & + & + & + & + & + & + & + \\
\hline $\mathrm{ADH}$ & Arginine & - & - & - & - & - & - & - & - & - & - \\
\hline URE & Urea & - & - & - & - & - & - & - & - & - & - \\
\hline ESC & Esculin & + & + & + & + & + & + & + & + & + & + \\
\hline GEL & Gelatine & - & - & - & - & - & - & - & - & - & - \\
\hline PNPG & $\beta$ galactopyranoside & + & + & + & + & + & + & + & + & + & + \\
\hline GLU & Glucose & + & + & + & + & + & + & + & + & + & + \\
\hline ARA & Arabinose & + & + & + & + & + & + & + & + & + & + \\
\hline MNE & Mannose & + & + & + & + & + & + & + & + & + & + \\
\hline MAN & Manitol & + & + & + & + & + & + & + & + & + & + \\
\hline NAG & $\mathrm{N}$-acetyl-glucosamine & + & + & + & + & + & + & + & + & + & + \\
\hline MAL & Maltose & + & + & + & + & + & + & + & + & + & + \\
\hline GNT & Gluconate & - & - & - & - & - & - & - & - & - & - \\
\hline $\mathrm{CAP}$ & Caprate & - & - & - & - & - & - & - & - & - & - \\
\hline ADI & Adipate & - & - & - & - & - & - & - & - & - & - \\
\hline MLT & Malate & - & - & - & - & - & - & - & - & - & - \\
\hline CIT & Citrate & - & - & - & - & - & - & - & - & - & - \\
\hline $\mathrm{PAC}$ & Phenvl-acetate & - & - & - & - & - & - & - & - & - & - \\
\hline
\end{tabular}

(+) means that Rhizobia isolate has consumed the substrate (change the colour), ( - ) means that Rhizobia isolate had not consumed the substrate (no colour change). 
Tab. 4 API 20 E test results of the Rhizobium trifolii isolates after incubation at $28^{\circ} \mathrm{C}$ for 48 hours

\begin{tabular}{|c|c|c|c|c|c|c|c|c|c|c|c|}
\hline \multirow{2}{*}{ Tests } & \multirow{2}{*}{ Substrates } & \multicolumn{10}{|c|}{ Isolates } \\
\hline & & RtS1 & $\mathrm{RtS2}$ & RtS3 & RtS4 & RtS5 & RtR1 & RtR2 & RtR3 & RtR4 & RtR5 \\
\hline ONPG & $\beta$-Galactopyranosidase & + & + & + & + & + & + & + & + & + & + \\
\hline $\mathrm{ADH}$ & Arginine dihydrolase & - & - & - & - & - & - & - & - & - & - \\
\hline LDC & Lysine decarboxylase & - & - & - & - & - & - & - & - & - & - \\
\hline ODC & Ornithine decarboxylase & - & - & - & - & - & - & - & - & - & - \\
\hline $\mathrm{CIT}$ & Citrate utilization & - & - & - & - & - & - & - & - & - & - \\
\hline $\mathrm{H}_{3} \mathrm{~S}$ & $\mathrm{H}, \mathrm{S}$ production & - & - & - & - & - & - & - & - & - & - \\
\hline URE & Urease & + & + & + & + & + & + & + & + & + & + \\
\hline TDA & Tryptophane deaminase & + & + & + & + & + & + & + & + & + & + \\
\hline IND & Indole production & - & - & - & - & - & - & - & - & - & - \\
\hline VP & Voges Proskauer & - & - & - & - & - & - & - & - & - & - \\
\hline GEL & Gelatinase & - & - & - & - & - & - & - & - & - & - \\
\hline GLU & Glucose & + & + & + & + & + & + & + & + & + & + \\
\hline MAN & Mannitol & + & + & + & + & + & + & + & + & + & + \\
\hline INO & Inositol & + & + & + & + & + & + & + & + & + & + \\
\hline SOR & Sorbitol & + & + & + & + & + & + & + & + & + & + \\
\hline RHA & Rhamnose & + & + & + & + & + & + & + & + & + & + \\
\hline SAC & Saccharose & + & + & + & + & + & + & + & + & + & + \\
\hline MEL & Melibinose & + & + & + & + & + & + & + & + & + & + \\
\hline AMY & Amygdalin & - & - & - & - & - & - & - & - & - & - \\
\hline ARA & Arabinose & + & + & + & + & + & + & + & + & + & + \\
\hline
\end{tabular}

Tab. 5 API 20 E test results of the Sinorhizobium meliloti isolates after incubation at $28^{\circ} \mathrm{C}$ for 48 hours

\begin{tabular}{|c|c|c|c|c|c|c|c|c|c|c|c|}
\hline \multirow{2}{*}{ Tests } & \multirow{2}{*}{ Substrates } & \multicolumn{10}{|c|}{ Isolates } \\
\hline & & SmM1 & SmM2 & SmM3 & $\mathrm{SmM}_{4} \mathrm{~S}$ & SmM5 & SmI1 & $\mathrm{SmI} 2$ & $\mathrm{SmI} 3$ & $\mathrm{SmI4}$ & SmI5 \\
\hline ONPG & $\beta$-Galactopyranosidase & + & + & + & + & + & + & + & + & + & + \\
\hline $\mathrm{ADH}$ & Arginine dihydrolase & - & - & - & - & - & - & - & - & - & - \\
\hline $\mathrm{LDC}$ & Lysine decarboxylase & + & + & + & + & + & + & + & + & + & + \\
\hline ODC & $\begin{array}{l}\text { Ornithine } \\
\text { decarboxylase }\end{array}$ & + & + & + & + & + & + & + & + & + & + \\
\hline CIT & Citrate utilization & - & - & - & - & - & - & - & - & - & - \\
\hline $\mathrm{H}_{2} \mathrm{~S}$ & $\mathrm{H}_{2} \mathrm{~S}$ production & - & - & - & - & - & - & - & - & - & - \\
\hline URE & Urease & - & - & - & - & - & - & - & - & - & - \\
\hline TDA & $\begin{array}{l}\text { Tryptophane } \\
\text { deaminase }\end{array}$ & + & + & + & + & + & + & + & + & + & + \\
\hline IND & Indole production & - & - & - & - & - & - & - & - & - & - \\
\hline VP & Voges Proskauer & - & - & - & - & - & - & - & - & - & - \\
\hline GEL & Gelatinase & - & - & - & - & - & - & - & - & - & - \\
\hline GLU & Glucose & + & + & + & + & + & + & + & + & + & + \\
\hline MAN & Mannitol & + & + & + & + & + & + & + & + & + & + \\
\hline INO & Inositol & + & + & + & + & + & + & + & + & + & + \\
\hline SOR & Sorbitol & + & + & + & + & + & + & + & + & + & + \\
\hline $\mathrm{RHA}$ & Rhamnose & + & + & + & + & + & + & + & + & + & + \\
\hline SAC & Saccharose & + & + & + & + & + & + & + & + & + & + \\
\hline MEL & Melibinose & - & - & - & - & - & - & - & - & - & - \\
\hline AMY & Amygdalin & - & - & - & - & - & - & - & - & - & - \\
\hline ARA & Arabinose & + & + & + & + & + & + & + & + & + & + \\
\hline
\end{tabular}


20 NE system. Rhizobial isolates have not been able to consummate the substrate for potassium gluconate (GNT), capric acid (CAP), adipic acid (ADI). For malic acid (MLT) varied in the case of Rhizobium trifolii isolates and phenylacetic acid (PAC) tests was positive for the same isolates. Trisodium citrate (CIT) was variable for Rhizobium trifolii isoaltes (Tab 2). In the case Sinorhizobium meliloti on malic acid (MLT), trisodium citrate (CIT) and phenylacetic acid (PAC) tests was negative for all the isolates (Tab.3).

In API $20 \mathrm{E}$ some of the carbon sources were present in API $20 \mathrm{NE}$ (GLU, ARA and MAN) and the results were the same. Inositol (INO), D-sorbitol (SOR), rhamnose (RHA) and saccharose (SAC) the results emerged as positive according to the reading table for all the isolates. Melibinose (MEL) test was positive for RtS and RtR and negative for SmM and SmI and all isolates had a negative reaction to amygdalin (AMY). These findings are consistent with the results of Shahzad et al. (2012) who also reported these sugar tests positive during isolation and characterization of Sinorhizobium meliloti.

Regard to the variety of carbohydrates utilez by rhizobia many authors confirm our findings (Graham, 1964, Graham and Parker 1964, Hussain et al., 2002 and Ramírez-Bahena et al., 2008).

Two API system were performed to compare rhizobia isolated from red clover and alfalfa. Our results indicate that isolates selected to test are not so different biochemically. Both Rhizobium trifolii and Sinorhizobium meliloti indicates some particularity, however there are plenty of similarities shared between the two strains of rhizobia.

\section{CONCLUSION}

We can concluded that this fast-growig species of root-nodule Rhizobium trifolii and Sinorhizobium meliloti are closely related. Rhizobial strains utilized a wider range of carbohydrates and this carbon sources are helpful tool to characterize the rhizobial isolates.

Acknowledgments. This paper was published under the frame of European Social Fund, Human Resources Development Operational Programme 2007-2013, project no. POSDRU/159/1.5/ S/132765.

\section{REFERENCES}

1. Deshwal VK, Chaubey A (2014). Isolation and characterization of Rhizobium leguminosarum from root nodule of Pisum sativum L. Journal of Academia and Industrial Research (JAIR). 2(8):464-467.

2. Gachande BD, Khansole GS (2011). Morphological, cultural and biochemical characteristics of Rhizobium japonicum syn and Bradyrhizobium japonicum of soybean. Bioscience Discovery. 2(1):1-4.

3. Graham PH (1964). Studies on the utilization of carbohydrates and Krebs cycle intermediates by Rhizobia, using an agar plate method. Antonie von Leeuwenhoek. 30:68-72.

4. Graham PH, Parker CA (1964). Diagnostic features in the characterization of the root-nodule bacteria of legumes. Plant and Soil. 2(3):383-396.

5. Greenwood RM, Pankhurst CE (1977). The Rhizobium component of the nitrogen-fixing symbiosis. Proceedings N.Z. Grassland association. 167-174.

6. Hussain M, Ashraf M, Saleem M, Hafeez FY (2002). Isolation and characterization of rhizobial strains from alfalfa (Medicago sp.). Pak. J. Agri. Sci. 39:32-34.

7. Prayitno J, Rolfe B (2010). Characterization of endophytic diazotroph bacteria isolated from rice. Hayati Journal of Biosciences. 17(2):73-78.

8. Ramírez-Bahena MH, García-Fraile P, Peix A, Valverde A, Rivas P, Igual JM, Mateos PF, Martínez-Molina E, Valazquez E (2008). Revision of the taxonomic status of the species Rhizobium leguminosarum (Frank 1879) Frank $1889^{\mathrm{AL}}$, Rhizobium phaseoli Dangeard $1926^{\mathrm{AL}}$ and Rhizobium trifolii Dangeard $1926^{\mathrm{AL}}$. R. trifolii is later synonym of $R$. leguminosarum. Reclassification of the strain $R$. leguminosarum DSM 30132(=NCIMB 11478) as Rhizobium pisi sp. nov. International Journal of Systematic and Evolutionary Microbiology. 58:2484-2490.

9. Sadowsky MJ, Keyser HH, Bohlool BB (1983). Biochemical Characterization of fast-and slow-growing rhizobia that nodulate soybeans. International Journal of Systematic bacteriology. 33(4):716-722.

10. Sessitsch A, Howieson JG, Perret X, Antoun H, MartínezRomero E (2002). Advances in Rhizobium Research. Critical Reviews in Plant Sciences. 21(4):323-378.

11. Sharazad F, Shafee M, Abbas F, Babar S, Tariq MM, Ahmad $\mathrm{Z}$ (2012). Isoaltion and biochemical characterization of Rhizobium meliloti from root nodules of alfalfa (Medicago sativa). The Journal of Animal \& Plant Sciences. 22(2):522524.

12. Shetta ND, Al-Shaharani TS, Abdel-Aal M (2011). Identification and characterization of Rhizobium associated with woody legume trees grown under Saudi Arabia condition. American-Eurasian J. Agric. \& Environ. Sci. 10(3):410-418.

13. Shridhar BS (2012). Review:Nitrogen Fixing Microorgansims. International Journal of Microbiological Research. 3(1):46-52.

14. Zahran HH (2001). Rhizobia from wild legumes: diversity, taxonomy, ecology, nitrogen fixation and biotechnology. Journal of Biotechnology. 91:143-153. 